\title{
Marxismo, capitalismo e natureza: pensando algumas questões
}

\author{
Marxism, capitalism and nature: considering some questions
}

Luiz Marcos de Lima Jorge*

\begin{abstract}
Resumo - Este artigo apresenta algumas reflexões acerca dos impactos que o desenvolvimento do capitalismo traz à natureza. Privilegiouse uma análise histórica deste desenvolvimento na qual, num primeiro momento, discutimos a relação do homem com a natureza nas comunidades naturais ou primitivas. Em seguida, discutimos como a religião é uma marca importante nesta relação homem e natureza. A reflexão se desdobra nos elementos que permitem pensar esta natureza como paisagem, em que o turismo é uma das formas de fazer com que esta natureza gere valor. O estudo aborda também o conceito de "sociedade do espetáculo", no qual a natureza transformada em paisagem e a paisagem transformada em mercadoria é contemplada de forma passiva, como espetáculo, por aqueles que podem desfrutar deste artigo de luxo.
\end{abstract}

Palavras-chave: capitalismo; natureza; mercadoria; espetáculo; turismo.

\begin{abstract}
This article presents considerations on the impact on nature of the evolution of capitalism. A historical analysis of this development was favored, in which we examined the relationship between men and nature in natural and primitive societies. Next, we discussed how religion is an important factor in this relation. The reflection includes elements that allows us to consider nature as landscape, in which tourism is one of the ways to make it profitable. Also, the study also approaches the concept of "society of the spectacle", in which nature is turned into landscape, and landscape as a commodity is contemplated passively as a spectacle by those who can savor this luxury item.

Keywords: capitalism; nature; commodity; spectacle; tourism.
\end{abstract}

\footnotetext{
* Doutor em Serviço Social pela Universidade Federal do Rio de Janeiro e Professor Associado da Escola de Serviço Social da Universidade Federal Fluminense. Correspondência: Rua Fábio Luz, 460/apt 602 - Méier - Rio de Janeiro -RJ-CEP:20720-350. E-mail: <jovialmariana@uol.com.br>
} 


\section{Introdução}

No início do século XXI, a questão da destruição da natureza e a necessidade da preservação ambiental aparecem com urgência nos debates. A escassez dos recursos naturais, a crise hídrica, o aquecimento global, a produção de transgênicos e as catástrofes "naturais" demonstram, entre outros aspectos, um esgotamento de uma forma social na qual o que conta é a produção ilimitada do valor.

O que chama atenção é que há algumas décadas atrás, quando se debatia sobre os problemas ecológicos, os autores se referiam a eles como algo muito distante, um futuro longínquo que nos atingiria num período aproximado de cem anos. Com o tempo, fomos observando que atingir esta marca histórica na configuração do desastre era uma questão muito próxima.

O processo de devastação da natureza, de deterioração do meio ambiente e de mudanças climáticas se acelerou a tal ponto que não estamos mais discutindo um futuro a longo prazo. Estamos discutindo, na verdade, processos que já estão em curso e, diferentemente do que é difundido, toda esta degradação não é resultado do excesso de população, da falta de ações educativas para a preservação ambiental. O que observamos é que estes processos resultam de algo muito concreto: as consequências do processo de acumulação do capital, em particular, da sua forma atual, em que esta acumulação somente pode ocorrer por meio de destruições.

Portanto, do ponto de vista da lógica do capital, que é exatamente o da globalização competitiva, destruir a natureza torna-se uma forma de gerar valor. Se nas comunidades primitivas, ou "comunidades naturais", como se referia Marx (1983), o trabalho como produtor de valores de uso aparecia como uma necessidade eterna da humanidade, uma necessidade insuprimível da vida humana, no capitalismo o que conta é o trabalho abstrato.

Este artigo apresenta algumas reflexões sobre esta forma social na qual até mesmo a natureza se torna algo instrumental, que pode ser manipulada e modificada pelo trabalho humano. Um exemplo desta manipulação é a transformação da natureza em paisagem e a consequente exploração desta paisagem através das atividades turísticas. Privilegiamos inicialmente uma abordagem histórica do trabalho como categoria que dá origem a um novo tipo de ser, o ser social. Em seguida, analisamos como este trabalho vai se modificando com o advento da sociedade burguesa até chegarmos no conceito de "sociedade do espetáculo": uma sociedade onde tudo tem que ser espetacular, onde a mercadoria é o totem em torno do qual os habitantes organizam a sua vida. 


\section{A contemplação e a perda do "paraíso". Alguns elementos da história}

Quando Marx (1983, p. 45), no século XIX, afirmou que a riqueza da sociedade burguesa "era uma imensa coleção de mercadorias", isto não significava apenas uma constatação empírica, fruto de uma curiosidade intelectual; significava que aquela sociedade obedecia a uma dinâmica própria, diferente de todas as formas sociais anteriores.

O duplo valor da mercadoria dava uma identidade particular a esta forma de produção: os produtos criados pelo homem tinham um valor de uso. No entanto, exigia que estes produtos apresentassem um valor de troca, ou seja, o caráter social do trabalho era realizado de forma privada e estranhada. Não estávamos mais diante das formas comunais da propriedade da terra, em que o consumo dos produtos retirados da natureza era destinado à família ou à tribo; frente a uma simples ou inexistente divisão social do trabalho, a relação entre o homem e a natureza não aparecia como relação estranhada.

Na sociedade burguesa, a utilidade de um determinado objeto é uma produção social efetivada para satisfazer a necessidade de outra pessoa. O objeto deve ser útil imediatamente não para quem o faz, mas para quem vai consumi-lo após o processo de troca. Nesta forma social em que consumo e produção estão apartados, o homem é o resultado deste processo em outras palavras, a existência humana é produto de uma relação de troca.

O trabalho aparece como modus operandi pois, na sociedade burguesa, ele é um meio de alterar as formas materiais. Mas este trabalho não é o elemento da efetividade humana, a essência do ser humano criativo. É o trabalho estranhado, no qual o metabolismo com a natureza não faz deste homem um ser liberto das formas alienadas. Pelo contrário, o que conta é o trabalho abstrato, pois o homem não se reconhece nele, nos produtos que este trabalho cria; as expressões objetivas do mesmo trabalho - que podem ser materializadas em diferentes produtos, ou seja, podem ser um casaco, uma bolsa, uma cesta artesanal - aparecem como "dispêndio produtivo de cérebros, músculos, nervos, mãos, etc." (MARX, 1983, p. 51).

Nas comunidades naturais, ou nas formas que precederam o modo de produção capitalista", como descreve Marx (2011, p. 389), o espaço do consumo era o mesmo lugar da produção; não havia a separação do trabalho livre das condições objetivas da sua produção. O metabolismo entre o homem e a natureza não aparecia como forma de produção de excedentes. O trabalho, como categoria fundante do ser social, transformava a natureza com o objetivo de criar os bens materiais necessários à existência humana. É um trabalho concreto e, por isto, fundante da sociabilidade humana.

As comunidades primitivas apresentavam esta particularidade, ou seja, o indivíduo produzia para a satisfação das suas necessidades e as de 
sua família. Se a produção gerava algum excedente, era para ser partilhado entre os membros da comunidade. É um contexto onde a esfera da produção não aparece apartada da esfera do consumo, na qual os indivíduos produzem para a satisfação das necessidades imediatas. O homem desenvolve uma relação com a natureza em que o trabalho aparece sem a mediação e sem o estranhamento do mercado e do dinheiro.

Com o desenvolvimento da produção mercantil, as formas de mediação entre o homem e a natureza começam a ser modificadas. É um estágio civilizatório em que se observa que a divisão social do trabalho se apresenta mais desenvolvida. A regra dominante é, agora, a apropriação individual - o produtor separa-se do seu produto na troca, que passa não apenas de mão em mão, mas de mercado para mercado. Engels (1985, p. 197) faz uma observação importante desta fase da civilização, diferente das formas anteriores, daquilo que o autor chama de "Estado Selvagem e da Barbárie":

[...] os produtores já deixaram de ser senhores da produção total das condições da sua própria vida e tampouco os comerciantes chegaram a sê-lo. Os produtos e a produção estão entregues ao acaso.

O aprofundamento da divisão do trabalho torna mais complexa e heterogênea a relação entre os indivíduos, antes subsumidos à comunidade e à natureza. A diferenciação na divisão social do trabalho permite observar a contradição entre os interesses individuais e os interesses coletivos, o que demostra a consolidação de um processo histórico em que a ação do homem se volta contra ele, como um poder estranho. A atividade humana passa a ser algo que subjuga o homem, que se apresenta acima dele e que lhe foge ao controle. ${ }^{1}$

A sociedade grega é um exemplo significativo neste processo de transformação na relação entre o homem e a natureza. A introdução do trabalho escravo em larga escala, no século $V$ a.C., altera a vida econômica de Atenas, como também proporciona a reestruturação da vida sociopolítica. A contradição estrutural de Atenas estava na sua base material, ou seja, era uma sociedade na qual o comércio despontava como elemento de dissolução das formas naturais e arcaicas, mas que, ao mesmo tempo, baseava-se no trabalho escravo. Isto demarcava os limites da sua própria forma.

A democracia direta acabava sendo dirigida por aqueles que tinham as melhores condições culturais, filhos de famílias ricas, que terminavam por legislar em causa própria. O advento da pólis aparece como seu inverso: a necessidade de um mercado que garantisse a satisfação das

\footnotetext{
${ }^{1}$ Na Ideologia Alemã, Marx e Engels (2009) ressaltam que o trabalho dá origem a um novo ser social. No entanto, eles se referem a um trabalho concreto, livre de qualquer abstração. É uma atividade vital pois, ao se relacionar com a natureza, o homem retira dela as condições da sua reprodução.
} 
necessidades dos homens teria que ser suprida pelo trabalho de outras pessoas (escravos). A existência de indivíduos livres, independentes e atomizados não aparece como algo contraditório numa sociedade na qual os interesses privados e a consolidação do mercado ganham cada vez mais destaque.

A crise que envolve a pólis atinge o núcleo central do pensamento e da forma de vida, que não está mais voltada para o ethos comunitário; as preocupações se voltam para os problemas da lei, da política e da conduta moral.

Aristóteles (384 a.C.-322 a.C.) se depara com esta realidade em transformação. O metabolismo com a natureza começa a ser mediado por formas estranhadas, por relações mercantis; neste sentido, Aristóteles (1996, p. 122) critica essa forma de vida, alicerçada na busca pelo dinheiro:

A vida dedicada a ganhar dinheiro é vivida sob compulsão, e obviamente ela não é um bem que estamos procurando; trata-se de uma vida apenas proveitosa e com vista a algo mais. Sob este prisma os objetivos que acabamos de mencionar podem ser tidos como fins, pois eles podem ser apreciados por si mesmos. É evidente, porém, que eles não são bens autênticos, mas muitos argumentos foram gastos para sustentá-los. Deixemos então de lado esse assunto.

Aristóteles defronta-se com uma Atenas onde a mediação da política substitui - de forma progressiva, tendo em vista o incremento das atividades mercantis desencadeadas desde o século VIII a.C. - a relação entre o homem e a natureza. Como a escravidão ainda é um obstáculo para o desenvolvimento mercantil, os próprios limites da formação social grega permitem a Aristóteles realizar a mímesis, ou seja, o homem grego ainda está misturado à natureza. Neste sentido, a contemplação revela um sentimento de pertencimento num mundo onde o que conta é o valor de uso. Em outras palavras, é uma realidade em que a divisão do trabalho ainda comporta a mão de obra escrava como um dos seus fundamentos.

Marx (1983) afirma, em O capital, o "incômodo" do estagirita em relação a esta forma de equivalente. Segundo Marx (1983, p. 62):

As duas peculiaridades da forma equivalente desenvolvidas por último tornam ainda mais palpáveis quando retornamos ao grande pesquisador que primeiro analisou a forma de valor, assim como muitas formas de pensamento da sociedade e da natureza. Este é Aristóteles. De início declara Aristóteles claramente que a forma dinheiro da mercadoria é apenas a figura mais desenvolvida da forma simples do valor, isto é, da expressão do valor de uma mercadoria em outra qualquer. [...] ele reconhece, ademais, que a relação de valor, em que essa expressão de valor está contida, condiciona por seu lado que a casa é equiparada qualitativamente à almofada e que essas coisas perceptivelmente diferentes, sem tal igualdade de essências, não poderiam ser relacionadas entre si, como grandezas comensuráveis. A troca, diz ele, 'não pode existir sem igualdade, nem 


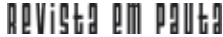

\} MARXISMO, CAPITALISMO E NATUREZA - JORGE, L. M. L. \}

igualdade sem a comensurabilidade'. Mas aqui ele se detém desconfiado e renuncia a seguir, analisando a forma valor.

Se o dinheiro é, para Aristóteles um mistério, este modo de equiparar coisas completamente diferentes revela formas desenvolvidas de um sociometabolismo, no qual a natureza vai se tornando algo meramente instrumental, transformando-se num objeto que pode ser quantificado e modificado. O homem não interage mais com a natureza para retirar dela apenas o seu sustento e o da sua família. A mímesis não é mais a mistura, mas a representação de um processo no qual o homem precisa de critérios abstratos para pensar esta natureza e representá-la quantitativamente. ${ }^{2}$

A dissolução da sociedade grega representa, na sua singularidade, as transformações que marcam uma nova forma de metabolismo do homem frente à natureza. A noção de mercado, da troca mercantil - na sua forma mais desenvolvida - só se desenvolve muito tempo depois. Ela não ocorre abruptamente, exigindo todo um processo de transformações para formas mais complexas de sociabilidade. Mas é fato que essas formas de mediação vão se transformando, adquirindo uma complexidade e abrangendo dois elementos importantes e que estarão presentes no decorrer da Idade Média: a terra e o comércio. ${ }^{3}$

Num primeiro momento, a interseção das rotas comerciais motivava a formação de pequenas praças, onde as pessoas se reuniam para trocar os produtos. Posteriormente, essas pequenas praças se transformam em locais onde a movimentação dos indivíduos era intensa; a formação dos burgos e, depois, o desenvolvimento das cidades acelera um processo de urbanização e consolida a troca de produtos e um significativo fluxo comercial.

A Idade Média é o momento histórico no qual o comércio e as trocas inauguram uma forma de relação do homem com os produtos do trabalho e com a natureza. Nessa relação, este trabalho e esta natureza são convertidos em objeto para suprir ou cumprir uma necessidade, e nada além disto. Quando a natureza é um mero objeto, ela tem que estar subordinada aos interesses universais, ou seja, ela não apresenta apenas valor de uso que está presente em todas as mercadorias -, mas tem que apre-sentar um valor, ou melhor, gerar um valor. Como descreve Menegat (2012, p. 25):

O domínio absoluto do capital, isto é, a transformação de tudo em mercadorias, realiza-se, na relação dos seres humanos com a natureza, na forma de uma manipulação total desta. A própria natureza se torna um sistema fabricado pela sociedade por meio de grandes complexos financeiro-agroindustriais.

\footnotetext{
${ }^{2}$ Sobre as transformações da sociedade grega e os impactos na arte, na música, no teatro ver: Pierre-Maxime Schull (2010).

${ }^{3}$ Para aprofundar esta processualidade histórica ver: Hilário Franco Junior (2010).
} 
Outro elemento importante na Idade Média é a ideia do Deus único. O monoteísmo não apenas substitui o culto a vários deuses, mas imprime uma marca nas relações e formas sociais nesse período histórico. Diante de indivíduos atomizados, o Cristianismo vai cumprir esta função de reunir o que está disperso. O mesmo Deus que cria a natureza é aquele que cria os homens; é significativo que a elaboração de conceitos universais justifique formas de exploração da natureza e dos homens entre si, ou seja, esta suposta universalidade unifica a experiência de atomização. A religião e o dinheiro cumprem este papel.

Se, na Idade Média, ainda não temos uma sociedade produtora de mercadorias ou, como afirma Marx (1983), a riqueza da sociedade não aparece como uma "imensa coleção de mercadorias", o culto ao Deus abs-trato é uma forma de ocultamento da realidade. E qual é a realidade a ser ocultada? A realidade na qual a natureza vai se tornando algo racional, resultado de um processo histórico de separação e atomização. O que é racional é a reprodução do dinheiro pelo dinheiro - algo que ganha maturidade com a emergência da sociedade capitalista.

É significativo que, numa sociedade onde a Igreja exerce o poder através do domínio das terras e onde as relações sociais começam a ser mediadas pelo dinheiro, a figura histórica de Francisco di Bernardone conhecido entre nós como Francisco de Assis - desponte entre os séculos XII-XIII como personagem que busca uma relação com a natureza para além dos limites impostos pelo mercado e pelo dinheiro. Num momento em que a atividade mercantil passa a desempenhar um papel central na vida do Ocidente, Francisco se contrapõe às formas de mediação nas quais o dinheiro começava a fazer os seus estragos.

Se inicialmente, na sua juventude, Francisco gostava de aproveitar o tempo livre para cantar pelos vilarejos de Assis, a busca desse tempo livre aparecia como protesto contra o comércio, que sujeitava o ser humano e o levava aos limites estreitos de uma sociedade mercantil. A condenação ao dinheiro e à propriedade privada indicava a necessidade - posteriormente marcada em Francisco pelo elemento religioso - de construir uma sociedade nova e igualitária, construir um caminho que levasse à superação de formas mediativas que faziam da natureza um mero objeto. ${ }^{4}$

A recusa de Francisco à propriedade privada e ao dinheiro resgata, em sua singularidade, a busca de uma forma social próxima àquela vivida na Grécia: o retorno à mímesis (mistura) como meio para a construção de uma ordem societária na qual a natureza não seja mero instrumento a serviço dos interesses mercantis. Mas aquela mímesis, em que o que contava era o valor de uso, estava irremediavelmente perdida.

\footnotetext{
${ }^{4}$ Para um maior aprofundamento da biografia de Francisco di Bernardone e de seus escritos, ver: Leonardo Boff (1985) e Celso Mário Teixeira (2008).
} 


\section{A natureza como algo terreno... e estranhado}

Em Manuscritos econômicos-filosóficos, de 1844, Marx faz referência ao trabalho como categoria que dá origem a um novo ser social. O trabalho aparece como fundamento ontológico, pois é por meio dele que o homem se objetiva; qualquer forma de sociabilidade teria no trabalho o tipo de atividade que, modificando a natureza, construiria a base material da sociedade. Segundo Marx (2010, p. 84):

Pois primeiramente o trabalho, a atividade vital, a vida produtiva mesma aparece ao homem apenas como um meio para a satisfação de uma carência, a necessidade de manutenção da existência física. Avida produtiva é, porém, a vida genérica. A vida produtiva é, porém, a vida genérica. É vida engendradora de vida.

Num outro momento, em O capital, Marx (1983, p. 149) descreve que o trabalho é, "antes de tudo, um processo entre o homem e a Natureza, um processo em que o homem, por sua própria ação, media, regula e controla seu metabolismo com a Natureza". Em ambas as citações, Marx não se refere ao trabalho concreto, mas a elementos essenciais e universais do trabalho.

No entanto, no capitalismo, esse trabalho ganha uma particularidade: é o trabalho alienado que permite ao homem garantir - e nada mais do que isso - a sua existência material. O produto do trabalho, resultante da relação entre o homem e a natureza, aparece como "potência estranha", propriedade privada de outra pessoa que não o trabalhador. No mundo da mercadoria, o que conta é a produção interminável do excedente e o aprofundamento do trabalho alienado. Na medida em que se que aprofundam as relações de produção e a divisão social do trabalho, a essência humana fica reduzida ao ter, à utilidade da coisa, pois a objetivação do homem - que se dá na possibilidade de transformar a natureza pelo trabalho criativo, rico de suas potencialidades - é construída de forma inversa, pela máxima alienação dos homens.

Marx não se interessa pela natureza como problema abstrato ou metafísico, mas conectada à história universal, modificada pelo homem através do trabalho. Se o trabalho poderia se constituir numa atividade para o homem se realizar existencialmente, isto não acontece no modo de produção capitalista. A divisão sociotécnica do trabalho e a sua crescente mecanização geraram no indivíduo uma contínua repulsa a esta forma de trabalho. O metabolismo com a natureza acontece de forma estranhada, pois, como o sujeito não se reconhece naquilo que produz, é reduzido à condição de mera coisa, completamente desumanizado, reforçando aquilo que Marx (2010, p. 80.) analisa em Manuscritos, onde diz que o "trabalho se torna mais pobre, quanto mais riqueza produz, quanto mais a sua produção aumenta em poder e extensão." 


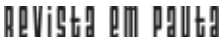

\} MARXISMO, CAPITALISMO E NATUREZA - JORGE, L. M. L. \}

Considerando que os meio de trabalho não são apenas medidores do grau de desenvolvimento das forças produtivas, mas também indicadores das condições nas quais se trabalha, na sociedade burguesa a natureza modificada pelo trabalho humano - tem que se tornar algo abstrato, um objeto meramente instrumental; tem que gerar valor. Esta natureza - agora uma propriedade do capitalista - não tem apenas um valor de uso, mas tem que engendrar um valor, fazer parte do processo de geração ilimitada de valor.

Neste contexto, a natureza torna-se puro objeto para o homem, aquilo que Marx (2011, p. 334) descreve como "pura utilidade da coisa", rompendo os desenvolvimentos locais; a natureza se submete às necessidades humanas, seja como objeto de consumo, seja como meio de produção. A própria produção cria, de fato, novas demandas, uma vez que sempre existe a possibilidade de empregar mais trabalhadores (que não ficam mais circunscritos ao trabalho na indústria), por meio das quais se criam novos ramos com o objetivo de gerar valor. Um dos ramos que se destacam neste processo é o turismo.

Evidentemente, o turismo que se desenvolve no início do capitalismo industrial é substancialmente diferente do turismo que conhecemos - que se consolida na segunda metade do século XX (o turismo ligado à atividade de lazer e descanso). Segundo Hobsbawm (2010, p. 296), no início do século XIX ocorria o deslocamento de grandes contingentes populacionais, um "êxodo rural em direção às cidades, a migração entre regiões e de cidades, o cruzamento de oceanos e a penetração em zonas de fronteiras", um fluxo de homens e de mulheres em todas as direções.

Num primeiro momento, o que motivava esse deslocamento era a necessidade de conseguir trabalho, emigrando do campo para a cidade. A primeira onda migratória da Inglaterra para a América foi essencialmente a fuga da fome, ou seja, a viagem para o pobre era, essencialmente, a busca por trabalho.

Ainda de acordo com Hobsbawm (2010), se a forma de viagem para o pobre era a migração, para a "classe média" e para os ricos as viagens significavam o turismo como forma de lazer e diversão, algo facilitado pela estrada de ferro, pelo barco a vapor e pela rapidez das comunicações postais. Se os homens pobres viajavam por necessidade - raramente conjugando trabalho e lazer, algo que vamos observar com outras características a partir da segunda metade do século XX -, o capitalismo industrial produzia novas formas de apropriação da natureza, que se materializavam nas viagens de lazer, "viagens de verão para a burguesia e pequenas excursões mecanizadas para as massas". (HOBSBAWM, 2010, p. 310).

Observa-se que, da mesma forma que a economia burguesa captura o tempo de trabalho excedente, o tempo livre também é capturado, mesmo nos momentos em que o indivíduo esteja voltado para atividades "não produtivas", como o lazer. Cada momento da existência aparece como 
momento da produção, para a produção de mais valor. Se as relações sociais de trabalho se caracterizam (no capitalismo) pela desapropriação dos meios de produção daquele que é o sujeito deste processo - o trabalhador, que tem a necessidade de vender a sua força de trabalho para se reproduzir, uma necessidade que se constituiu histórica e arbitrariamente -, com o advento da modernidade até mesmo o tempo livre é privatizado; a necessidade do ócio é enaltecida na (sempre) possível rentabilidade das atividades vinculadas ao lazer.

Em Grundrisse, Marx (2011), ao falar sobre o capital fixo e o desenvolvimento das forças produtivas da sociedade, descreve que, à medida que a grande indústria se desenvolve, a criação da riqueza passa a depender menos do tempo de trabalho e do quantum do trabalho empregado.

Marx (2011, p. 588) acreditava que, no desenvolvimento da sociedade burguesa, a indústria ocuparia a "grande coluna de sustentação da riqueza". O trabalho, na sua forma imediata, "o dispêndio de força humana de trabalho", que faz como que atividades qualitativamente diferentes possam ser igualadas, deixaria de ser a "grande fonte de riqueza e o tempo de trabalho não seria mais a sua medida; como consequência, o valor de troca deixaria de ser a medida do valor de uso".

Este certo otimismo de Marx se baseava na possibilidade de as pessoas desenvolverem a livre individualidade, disporem do tempo livre para se dedicarem a atividades artísticas e culturais. Surge, aqui, a ideia da disposição deste tempo por parte do ser humano para ser empregado em atividades criativas e libertadoras.

No entanto, o processo histórico tomou caminhos diferentes àqueles preconizados por Marx (2011). O alto desenvolvimento das forças produtivas não possibilitou que a economia do tempo de trabalho se transformasse para além do processo de geração do valor. Pelo contrário, o capital diminuiu o tempo de trabalho para aumentá-lo, por exemplo, na forma do supérfluo, no qual o turismo é uma das formas visíveis.

O desenvolvimento da tecnologia capitalista capturou este tempo livre, e o aprofundamento da divisão do trabalho, com a crescente mecanização, gera no trabalhador uma repulsa por esta atividade maçante e incapaz de lhe proporcionar uma satisfação existencial. O trabalho se torna apenas um meio para que o sujeito obtenha o necessário para a sua reprodução; na verdade, uma subvida.

A técnica torna-se a essência de uma produção e de um saber no qual o que conta é a exploração do trabalho dos outros, ou seja, o que os homens querem aprender com a natureza não é a contemplação do belo ou do artístico, mas como empregá-la para dominar completamente a ela e aos outros homens. Nesta relação, a essência das coisas revela-se sempre como dominação, mesmo porque a natureza deve ser dominada pelo trabalho, assim como o tempo livre. 


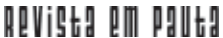

\} MARXISMO, CAPITALISMO E NATUREZA - JORGE, L. M. L. \}

Num mundo em que o indivíduo é reduzido à condição de merca coisa, completamente desumanizado, o próprio ócio do homem é utilizado com o objetivo de mecanizá-lo, de tal modo que, no capitalismo, nas suas formas mais avançadas, a diversão e o lazer tornam-se um prolongamento do trabalho. $\mathrm{O}$ "tempo livre industrializado" ${ }^{5}$ demonstra que a necessidade de gerar valor conquistou tamanho poder sobre os homens que, durante o tempo livre, eles procuram refazer suas energias para, em seguida, retornar ao trabalho - e aqui não apenas a natureza transformada em paisagem, contemplada através do turismo, cumpre esta função, mas todo produto do lazer e da distração fazem parte desta lógica.

Recorrendo à análise de Adorno e Horkheimer (2006), a ideologia da "indústria cultural" é o negócio. Ela provém de sua identificação com a necessidade produzida - e aqui sobressai a ideia de que primeiro a sociedade burguesa produz a mercadoria e depois, por caminhos que envolvem a comercialização, imagem, propaganda e marketing, a necessidade do produto. A promessa do descanso se concilia na exploração do sujeito e da natureza, em que a diversão cumpre a tarefa fantástica e ilusória de um sossego material e subjetivamente inexistente.

A diversão é o prolongamento do trabalho sob o capitalismo tardio. Ela é procurada por quem quer escapar ao processo de trabalho mecanizado, para se pôr de novo em condições de enfrentá-lo. Mas, ao mesmo tempo, a mecanização atingiu um tal poderio sobre a pessoa em seu lazer e sobre a sua felicidade, ela determina tão profundamente a fabricação das mercadorias destinadas à diversão, que esta pessoa não pode mais perceber outra coisa senão as cópias que reproduzem o próprio processo de trabalho. (ADORNO; HORKHEIMER, 2006, p. 113).

Como escapar da monotonia supõe - para aqueles que usam o transporte rodoviário - passar dez, doze horas nos engarrafamentos (o quantitativo aqui é o que menos importa), o que conta é que o tempo de ócio e de lazer destes turistas serve apenas para repor sua capacidade de trabalho. O suplício do tempo parado no trânsito caótico vale o sacrifício para retornar revigorado e, cada vez mais, atomizado e solitário. Na verdade, qualquer deslocamento de pessoas se enquadra nesta perspectiva, mesmo porque o tempo qualitativo se dilui no fluxo vazio entre os espaços.

Se o acesso ao turismo é tomado como forma de progresso da civilização, este progresso significa, para o indivíduo, o distanciamento e a separação da natureza, que precisa ser submetida às condições mercantis para a satisfação das necessidades humanas.

Neste contexto, a ideia do espetáculo é significativa para a compreensão da forma social que envolve as atividades do turismo. Quando a

\footnotetext{
${ }^{5}$ Esta denominação é utilizada por Renato Nunes Bittencourt (2013) para analisar a captura do tempo livre pelo capital.
} 


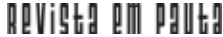

\} MARXISMO, CAPITALISMO E NATUREZA - JORGE, L. M. L. \}

paisagem é transformada em mercadoria, ela precisa ser divulgada, vendida, fazer parte da lógica do entretenimento. A "crítica radical" do espetáculo, formulada por Debord (2009), contribui para o entendimento deste fenômeno, a dominação do homem sobre a natureza, e como esta relação produz o espetáculo da mercadoria.

O conceito de "sociedade do espetáculo" não está restrito a uma crítica da televisão ou de outros meios mediáticos. O funcionamento dos meios de comunicação de massa, por um lado, tem seu conteúdo restrito; por outro, é expressão da sociedade da qual faz parte. Se, para Marx (1983), a riqueza da sociedade aparece como uma "imensa coleção de mercadorias", Debord (2009, p. 13) afirma que "toda a vida das sociedades, nas quais reinam as modernas condições de produção se apresenta como uma imensa coleção de espetáculos". Na sociedade do espetáculo não existe a relação direta entre o indivíduo e o seu mundo, apesar deste mundo ser produzido por ele. A contemplação passiva das imagens, que ademais foram escolhidas pelos outros, substitui o vivido - trata-se de uma sociedade baseada na contemplação passiva, na qual os indivíduos, em vez de viverem em primeira pessoa, olham a ação dos outros.

O espetáculo, portanto, não ficaria restrito a um conjunto de imagens, que teria por objetivo apenas o entretenimento, "mas uma relação social entre o indivíduo, mediada por imagens", resultado e projeto de um modo de produção existente (DEBORD, 2009, p. 14).

Não por acaso, para Debord (2009), a marca desta sociedade é o fetichismo. A imagem e o espetáculo têm em comum a característica de reduzir a multiplicidade do real a uma única forma abstrata e equivalente. Da mesma forma que a mercadoria, o espetáculo seria o estágio supremo da abstração; como nada escapa à lógica da mercadoria, nada foge à forma do espetáculo, até mesmo a natureza.

Quando o indivíduo viaja, ele vai, de certa forma, por um determinado período de tempo, deixar o mundo em que vive. Ao buscar o refúgio na natureza, a paisagem, transformada em mercadoria, é o espetáculo da contemplação, não do belo, da arte, mesmo porque esta natureza é algo instrumental, separado do homem, um mero objeto. Expropriado da sua condição humana, este indivíduo se vê imobilizado no centro falsificado do movimento do seu mundo, no qual a contemplação do idílico é a realidade falseada, vivida ilusoriamente. Como afirma Debord (2009, p. 106) "a realidade do tempo foi substituída pela publicidade do tempo."

Como a realidade é uma aparência do real, "o bombardeiro publicitário" precisa vender algo que não existe, pois, o espetáculo tem que ser mais poderoso que o real. A preservação da natureza, por exemplo, é bombardeada pelas campanhas publicitárias, que enfatizam o"desenvolvimento sustentável", "turismo responsável", produção e sustentabilidade". É o "velho" discurso universal, mas que não se aplica a uma classe particular: os capitalistas. O universal se revela numa mera abstração, pois as ações 


\section{Revigta dil paltg}

\} MARXISMO, CAPITALISMO E NATUREZA - JORGE, L. M. L. \}

que visam à "preservação ambiental" são dirigidas para os moradores das áreas turísticas, para os visitantes, que irão repousar as suas consciências, mas que nunca atingem aqueles que constroem hotéis, resorts, pousadas etc. Aqui, a exigência primeira do espetáculo é que à paisagem se adequem as necessidades do capital e que os meios empregados para esta finalidade não levem em conta qualquer possibilidade de preservação. Pelo contrário, a "pseudopreservação" só vale para que esta natureza seja consumida.

$\mathrm{E}$, nesta sociedade espetacular, as leis abstratas se tornam um sistema coerente que a tudo penetra; o espetáculo é a ditadura totalitária do fragmento e, para isto, a presença, não dos trabalhadores, mas dos especialistas, é fundamental, pois este fragmento da realidade precisa ser explicado e interiorizado pelo sujeito. Quando Debord (2009, p. 126) afirma que "a cultura tornada integralmente mercadoria deve tornar a mercadoria vedete da sociedade espetacular", o conhecimento deve justificar esta sociedade fragmentada e constituir-se como ciência geral da falsa consciência. O pensamento sobre o real se volta para defender o aparente, uma "subcomunicação", que não se ocupa dos conflitos e contradições de classe afinal de contas, isto não aparece como algo espetacular. Toda a sociedade é submetida ao pensamento abstrato, à opinião do especialista - este detém o saber absoluto no qual a separação dos saberes é a chave para encobrir a realidade.

A fragmentação não se restringe apenas à separação de um aparato técnico de divisão de saberes, mas ao ocultamento de uma realidade que não pode ser questionada nos seus fundamentos que alicerçam a desigualdade. Se pensarmos na tão propalada "questão ambiental", talvez o entusiasmo seja a marca deste "clube dos contentes".

As previsões vão da total destruição do planeta (o que não deixa de ser uma realidade de um mundo que precisa ser destruído e recriado pela mercadoria) até a crença de que a economia verde é algo palpável. Nas "tragédias ambientais", os especialistas invadem, com seus conhecimentos específicos, a vida já resignada. O balcão do saber especializado é um espetáculo de variedades: desde os especialistas em gestão de risco até o cuidado que os pais devem ter com as crianças em casa, por ocasião das férias escolares. Neste quadro, a infelicidade humana é o material que compartilham com entusiasmo. ${ }^{6}$

Se a imagem pode servir ao esclarecimento, é certo que a forma social que envolve esta imagem não é a forma social que sustenta a mercadoria. A imagem de um mundo onde o princípio dinâmico é o seu esgotamento não é compatível com o horizonte histórico que tenha como primado a satisfação das necessidades e a realização das potencialidades humanas.

${ }^{6}$ Cabe aqui uma observação importante de Robert Kurz (1997, p. 146): "Os intelectuais estetizam a miséria e a exploram comercialmente; o sofrimento daqueles que passam fome são transformados em publicidade. O temperamento ditado pela lógica do mercado chegou a criar um culto à maldade". 


\section{Considerações finais}

Toda sociedade organiza de alguma maneira sua produção material ou, como chamava Marx (1983), seu "metabolismo com a natureza". No entanto, nas sociedades primitivas ou naturais essa organização se dava de acordo com outros critérios que não eram os da troca entre produtores formalmente independentes. No capitalismo, o trabalho tem uma dupla natureza: ele é ao mesmo tempo trabalho concreto e trabalho abstrato.

O que vamos perceber não é apenas a supremacia deste trabalho abstrato sobre o trabalho concreto. O que cria o laço social no capitalismo não é a qualidade do trabalho humano, mas o trabalho em sua quantidade, indiferenciado, sempre igual e submetido ao mecanismo fetichista do seu crescimento. Nele, a produção é organizada em torno do trabalho abstrato, a relação entre as pessoas já se constitui de uma maneira alienada, desposada do controle humano - aqui a natureza é apenas algo instrumental, um ramo da indústria e que deve seguir o seu curso.

Em nome deste crescimento, tudo deve ser ultrapassado: o trabaIho vivo, as medidas de tempo, a natureza. Como a forma contemporânea do acúmulo de acréscimo e reposição do capital é incessante, esta forma social precisar destruir e modificar sob a hegemonia do trabalho abstrato. Como afirma Matos (apud JAPPE, 2013, p. 11), "abstração não significa apenas que o trabalho concreto é subsumido pelo abstrato, mas que seus mecanismos de esvaziamento do sentido da produção são ao mesmo tempo perda do saber-viver."

Na sociedade espetacular, podemos até mesmo falar de "consciência ecológica", "consumo sustentável" e outras soluções mistificadoras, mas não há condições de romper este estado de coisas sem centrar forças contra o fetichismo da mercadoria. As consequências per-versas desta forma de acumulação apenas reverberam a intensidade e justeza da tese de hobesiana de que o homem é o lobo do homem.

Portanto, não se trata de lutar por uma sociedade sustentável. Por mais que as exigências apareçam como justificáveis, as conciliações sempre desembocam em realidades mais catastróficas. Uma sociedade "mais igualitária" apenas muda o tipo de injustiça. Como afirma Jappe (2013, p. 30), "não há como escapar dos constrangimentos estruturais do sistema democratizando o acesso às suas funções." 


\section{Referências}

ADORNO, T. W.; HORKHEIMER, M. Dialética do esclarecimento. Fragmentos filosóficos. Rio de Janeiro: Zahar. 2006.

ARISTÓTELES. Ética a Nicômaco. In: ARISTÓTELES. Os pensadores. São Paulo: Nova Cultural. 1996.

BITTENCOURT, R. N. O tempo livre industrializado. Filosofia, Ciência \& Vida, São Paulo, ano IV, ed. 79, fev. 2013.

BOFF, L. São Francisco de Assis: ternura e vigor. Petrópolis: Vozes. 1985.

DEBORD, G. A sociedade do espetáculo. Comentários sobre a sociedade do espetáculo. Rio de Janeiro: Contraponto. 2009.

ENGELS, F. A origem da família, da propriedade privada e do Estado. Rio de Janeiro: Civilização Brasileira. 1985.

FRANCO JUNIOR, H. A Idade Média, nascimento do Ocidente. São Paulo: Brasiliense. 2010.

HOBSBAWM, E. J. A era do capital. 1848-1875. São Paulo: Paz e Terra. 2010

JAPPE, Anselm. Crédito à morte. A decomposição do capitalismo e suas críticas. São Paulo: Hedra. 2013.

KURZ, R. Os últimos combates. Petrópolis: Vozes. 1997.

MARX, K. O capital. Vol. I, tomo I. São Paulo: Abril Cultural. 1983.

. Manuscritos econômico-filosóficos. São Paulo: Boitempo. 2010.

. Grundrisse. Manuscritos econômicos de 1857-1858. Esboços da

crítica da economia política. São Paulo: Boitempo. 2011.

MARX, K.; ENGELS, F. A ideologia alemã. São Paulo: Boitempo. 2009.

MENEGAT, M. Estudos sobre ruínas. Col. Pensamentos Criminológicos, n. 18. Rio de Janeiro: Revan. 2012.

SCHULL, P. M. Platão e a arte de seu tempo. São Paulo: Discurso Editorial/ Bacarolla. 2010.

TEIXEIRA, C. M. (org.). Fontes franciscanas e clarianas. Petrópolis: Vozes. 2008.

Recebido em 27 de março de 2015.

Aprovado para publicação em 15 de julho de 2015 